\title{
Study of Electrocardiographic Changes Associated with Acute Poisoning in Tanta Poison Center
}

\author{
Mona Mohammad Heshmat ${ }^{1}$, Aisha Ibrahim Maklad', Raghda Ghonimy \\ Elsheikh$^{2}$, Enas Ibrahim Elmadah', and Amira Amin Wahdan'
}

\footnotetext{
${ }^{1}$ Department of Forensic Medicine and Clinical Toxicology

${ }^{2}$ Department of Cardiology
}

Faculty of Medicine, Tanta University, Tanta, Egypt.

All rights reserved.

\begin{abstract}
Poisoning or intoxication is the occurrence of harmful effects resulting from exposure to a foreign substance. According to the Center for Disease Control, approximately 1 million of the 110 million annual emergency department (ED) visits are related to poisoning and other toxic effects. Electrocardiogram (ECG) is a noninvasive, relatively inexpensive diagnostic test that provides important information regarding not only the heart, but also non-cardiac events impacting the cardiac system. The aim of this study was to evaluate the electrocardiographic changes conducted on 282 cases of acute poisoning admitted to Tanta Poison Center, Faculty of Medicine, Tanta Emergency University Hospital during the period from the start of July - 2009 to the end of June - 2010. In order to fulfill this aim, each patient was subjected to history taking, complete physical examination, laboratory investigations and ECG analysis. This study found that poisons associated with ECG changes account for $58.5 \%$ of patients included in this study. Furthermore, $36.17 \%$ of patients are mainly in the middle age group between 20 and 30 years. Organophosphorus compounds (34.4\%) were responsible for most cases of intoxication of ECG changes. Sinus tachycardia (73.94\%) was the commonest ECG change among them. Followed by prolonged QT corrected for heart rate (QTc) interval $(21.82 \%)$ and sinus bradycardia $(11.51 \%)$.
\end{abstract}

Keywords Intoxication, poison center, ECG \& sinus tachycardia

\section{Introduction}

$\mathrm{P}$ oisoning or intoxication is the occurrence of harmful effects resulting from exposure to a foreign substance. Such effects may be local (i.e., limited to exposed body surface) or systemic (Irwin and Rippe's 2006). Poisoned patients frequently present in the emergency department (ED). According to the Center for Disease Control, approximately 1 million of the 110 million annual ED visits are related to poisonings and other toxic effects (McCaig and Nawar 2006). Furthermore, at least 2 million cases are reported to poison centers (PC) each year. The PC data demonstrate that cardiovascular drugs as a specific group rank $11^{\text {th }}$ among the most frequent ingested materials. However, many drugs in overdose can have effects on the electrocardiogram (ECG), not just those specifically marketed for those effects (Watson et al., 2004; Lai et al., 2006).
The ECG is a graphical recording of the electrical activity of the heart. This electrical activity initiates the heart's muscular contraction that pumps the blood to the body. The ECG records cardiac electrical currents (voltages, potentials) by means of metal electrodes placed on the surface of the body. These metal electrodes are placed on the arms, legs, and chest wall (Goldberger, 2006; Wagner, 2008). Importantly, the ECG serves as an essential diagnostic tool in the ED for those patients who present with chest pain, dyspnea, neurologic symptoms, toxic ingestion, syncopal episode, multisystem trauma, and altered mental status (Benner et al., 2007).

Numerous authorities have studied ECG changes encountered in patients with specific toxicity. For example, multiple reports have been published describing the ECG changes encountered in either tricyclic antidepressant (TCA) poisoning or digoxin 
exposure. Little clinical information, however, is found in the literature to address the general use of the ECG in the poisoned patient (Delk et al., 2007; Wells et al., 2008). The aim of this study was to evaluate the electrocardiographic changes associated with cases of acute poisoning admitted to Toxicology Unit, Tanta University Emergency Hospital.

\section{Patients and methods}

This study was a prospective study conducted on 282 adult patients suffering from acute toxicity with different types of poisons admitted to Tanta poison center, Faculty of Medicine, Tanta University, during the period from the start of July - 2009 to the end of June - 2010. Inclusion criteria were any adult patients suffering from acute exposure to toxic substance. While, exclusion criteria were as follows (Children, patients with history of cardiovascular disturbances or with multiple drug ingestion).

All cases were subjected to: History taking from the patient or his relatives through questionnaire (patient data sheet) with emphasis on (demographic data, past medical history, mode of poisoning, type of the poison, route of exposure, and time interval between occurrence of poisoning and arrival to the poison center), complete physical examination including (level of consciousness, vital signs specially the heart rate and blood pressure). Laboratory investigations done routinely in the center with emphasis on [arterial blood gas analysis and serum electrolytes ( $\mathrm{Na}, \mathrm{K} \& \mathrm{Ca})]$.

The twelve- lead ECG was done on arrival to the center (with examination of the ECG strip for the rate, rhythm, conduction intervals, cardiac axis, QRS complex, ST segments and T wave). The patient was connected to a monitor to follow the case until normalization of the ECG if there was any abnormality. The fate of the patient either recovery or discharge was recorded. The nature of poison involved was determined from the circumstantial evidence, reliable history, presentation of remaining container (if available) from which the poison had been consumed, suggestive clinical feature and improvement of the symptoms and signs of poisoning after administration of specific antidote (e.g. atropine and oximes in cases of OPCs poisoning). Treatment was not mentioned in any case as the purpose of the study was concerned with the ECG changes only. An informed consent was taken from each participant in the study after giving detailed information about the nature of the research work.

\section{Statistics}

Statistical presentation and analysis of the present study was conducted, using the mean, standard deviation, Mann-Whitney, student t- test, and Chi- square tests by SPSS V17. Level of significance was determined at $\mathrm{p}$-value $<0.05$.

\section{Results}

\section{Demographic data (age \& sex)}

In this study one hundred \& sixty five patients (58.51 $\%$ of the studied patients) had ECG changes while 117 patients $(41.49 \%$ of the studied patients) had normal ECG. The age of the patients included in this study (according to the inclusion and exclusion criteria) ranged between 18 to 67 years with a mean age of $27.532 \pm 12.347$. There was a prevalence of intoxication in the age group between 18 and 29 years (189 patients, $67.02 \%$ of all patients), followed by age group between 30 and 39 years (56 patients, $19.86 \%$ of all patients). The age of patients with ECG changes ranged between 18 and 67 years with a mean of 26.806 \pm 13.318 while those with no ECG changes ranged between 18 and 67 years with a mean of $28.556 \pm$ 10.803. There was no significant difference when comparing both groups ( $\mathrm{P}$ - value is $>0.05$ ) (Figure $1 \&$ Table 1).

Among the studied patients with ECG changes 39 patients $(23.64 \%)$ were males and 126 patients $(76.36 \%)$ were females while in patients with no ECG changes 51 patients $(43.59 \%$ ) were males and 66 patients $(56.41 \%)$ were females (Figure 2). There was significant statistical difference between both groups ( $\mathrm{P}$ - value is $<0.05$ ).

\section{Toxicological history}

\section{1- Circumstances of poisoning}

In this study, patients with no ECG changes were 34 patients $(29.06 \%)$ and were exposed to poisoning accidentally whereas 83 patients $(70.94 \%)$ were suicidal attempts. Patients with ECG changes accidental intake occurred in $35(21.21 \%)$ while attempted suicide occurred in 130 (78.79\%). There was no significant statistical difference between both groups as regard circumstances of poisoning P-value was (0.13) (Figure 3). Suicidal intake occurred in females $(90.1 \%)$ more than in males $(44.44 \%)$. In contrast to accidental intake 50 males (55.56\%) compared to 19 females $(9.9 \%)$. This was statistically significant $(\mathrm{P}<0.05)$ (Figure 4$)$.

\section{2- Route of intake}

Route of intake was studied in both groups. Among patients with ECG changes, the oral intake represented the most common route $(82.42 \%)$ followed by inhalational exposure $(11.52 \%)$ then combined routes including oral with cutaneous and inhalational with cutaneous ( $2.42 \%$ for both), cutaneous exposure alone represented the least common route $(1.21 \%)$ in this group. Among patients with no ECG changes, the oral intake also represented the most common route $(81.2$ $\%$ ) followed by the combined inhalational with 
cutaneous exposure $(8.55 \%)$ then inhalational exposure alone $(6.84 \%)$, while cutaneous exposure alone and smoking were the least common routes $(1.71$ $\%$ each). The comparison between both groups as regard the route of intake was statistically significant $(\mathrm{P}$ - value $<0.05)$ (Figure 5).

The correlation between the route of intake and circumstances of poisoning was also, studied in the current study. This revealed that in suicidal poisoning, the route of intake was only oral while in accidental poisoning, there were different routes including the inhalational exposure $(9.57 \%)$, oral intake $(7.09 \%)$, inhalational with cutaneous exposure $(4.96 \%)$, oral with cutaneous exposure $(1.42 \%)$, cutaneous exposure alone $(1.42 \%)$. and lastly smoking $(0.71 \%)$ (Figure $6)$.

\section{3-Delay time between exposure to the poison and arrival to the poison center}

The delay time between exposure to the poison and arrival to the poison center varied greatly among the studied patients. In patients with ECG changes it ranged between half an hour to 19 hours with a mean of $4.739 \pm 3.679$ hours, whereas in patients with no changes it ranged from half an hour to 18 hours with a mean of $3.880 \pm 3.861$ hours. There was significant statistical difference between both groups (Figure 7).

\section{4-Types of poisons}

In this study, poisons divided into 4 categories; therapeutic drugs (in 157 patients, $55.67 \%$ ), pesticides (in 97 patients, $38.66 \%$ of study patients), carbon monoxide [Co] (in 11 patients, $3.9 \%$ ) and corrosives (in 5 patients, $1.77 \%$ )(figure 8 ).

These 4 categories included 27 types of poisons (each one was studied for the presence or absence of ECG changes). Organophosphorus compounds [OPCs] were the most common type of poisons consumed in this study by 97 patients $(34.4 \%)$ with the highest number of patients with associated ECG changes in 49 patients $(50.52 \%)$, Furthermore 2 patients of them $(4.082 \%)$ associated with metabolic acidosis and 1 patient with respiratory acidosis $(2.040 \%)$. This was followed by theophylline in 28 patients $(9.93 \%)$, ECG changes, were detected in 21 patients $(75 \%)$ while, metabolic acidosis was detected in 2 patients with ECG changes (9.523\%). Antipsychotics were consumed by 15 patients $(5.32$ $\%)$, ECG changes were detected in 6 patients $(40 \%)$, antihypertensive by 14 patients $(4.96 \%)$, three types of antihypertensive drugs were included in this study; angiotensin converting enzyme inhibitors (captopril in 10 cases), vasodilators (nitroglycerin in 2 cases) and diuretics (frusemide in 2 cases), ECG changes were detected in 10 patients $(28.57 \%)$. Digitalis by 13 patients $(4.61 \%)$, ECG changes was detected in 11 patients $(84.62 \%)$. Cyclic antidepressants [CA] by 13 patients $(4.61 \%)$, ECG changes were detected in 12 patients $(92.31 \%)$. Zinc phosphide by 12 patients $(4.26$ $\%)$, ECG changes was detected in 6 patients $(50 \%)$. Carbamazepine [CBZ] by 12 patients $(4.26 \%)$ and ECG changes were detected in 11 patients $(91.67 \%)$. Co by 11 patients (3.9\%), ECG changes and metabolic acidosis were detected in 7 patients $(63.64 \%)$. Bblockers by 9 patients $(3.19 \%)$, ECG changes were detected in 4 patients $(44.44 \%)$. The rest of poisons represented small number of cases as follows: Tramadol by 6 patients $(2.13 \%)$, ECG changes were detected in only 2 patients $(33.33 \%)$ while, respiratory acidosis was detected in only 1 patient of them $(16.66 \%)$. Corrosives were encountered in 5 patients $(1.77 \%)$, ECG changes were present in 3 patients (60 $\%)$. Anti- migraine drugs in 4 patients $(1.42 \%)$, ECG changes were present in 2 patients $(50 \%)$. SSRIs by 4 patients $(1.42 \%)$, ECG changes were present in only 1 patient $(25 \%)$. Salicylate in 4 patients $(1.42 \%)$, ECG changes and metabolic acidosis were present in 2 patients $(50 \%)$. Valproic acid by 4 patients $(1.42 \%)$, ECG changes were present in 2 patients (50\%), Antihistaminic drugs by 4 females (1.42\%), ECG changes were detected in 2 patients. Levothyroxine, $B 2$ agonist (salbutamol), antibiotics and hashish: Each one of these drugs was taken by 3 patients $(1.06 \%$ for each). ECG changes were present in all cases with levothyroxine and salbutamol poisoning. While, no changes were detected with hashish and antibiotic overdose. Dexamethasone and anti-arrhythmic drugs (class Ic, Propafenone): Each one of these drugs was encountered by 2 females $(0.71 \%$ of total cases for each), with ECG changes were present in all cases. Heroin, calcium channel blockers (CCBs) and thinner: Each one of these drugs was encountered by only one patient $(0.35 \%$ for each) among total patients included in this study. ECG changes were present in patient with heroin overdose, while patients with $\mathrm{CCB}$ and thinner poisoning had no ECG changes.

\section{Results of clinical examination}

Clinical manifestations on admission were recorded in Table (2a \& b).

\section{Serum electrolytes (Table 3)}

\section{ECG findings}

As mentioned before 117 patients didn't have ECG changes while 165 had. Among patients with ECG changes, the most common was sinus tachycardia (122 patients, $73.94 \%$ ) followed by prolonged QTc interval (36 patients, $21.82 \%$ ) then sinus bradycardia (19 patients, $11.51 \%$ ), abnormal $\mathrm{T}$ wave (biphasic or inverted) (12 patients, $7.27 \%$ ) and prolonged PR interval (10 patients, $6.06 \%$ ). Other changes were less frequent (Figure 9 to figure 16). 
Table (1): Age characteristics among patients with and without ECG changes.

\begin{tabular}{|l|c|c|c|c|}
\hline \multirow{2}{*}{} & \multicolumn{2}{|c|}{ Age (years) } & \multicolumn{2}{c|}{ T-test } \\
\cline { 2 - 5 } & Range & Mean \pm SD & t & P-value \\
\hline Patients without ECG changes & $18-67$ & $28.56 \pm 10.81$ & 1.173 & 0.242 \\
\hline Patients with ECG changes & $18-67$ & $26.81 \pm 13.32$ & & \\
\hline
\end{tabular}

Table 2a: Comparison between GCS and vital signs among patients (282) with and without ECG changes.

\begin{tabular}{|l|c|c|c|c|c|c|}
\hline \multirow{2}{*}{ GCS \& vital signs } & \multicolumn{2}{|c|}{$\begin{array}{c}\text { Patients without ECG changes } \\
(\mathbf{n}=\mathbf{1 1 7})\end{array}$} & $\begin{array}{c}\text { Patients with ECG changes } \\
(\mathbf{n = 1 6 5})\end{array}$ & \multicolumn{2}{c|}{ T-test } \\
\cline { 2 - 7 } & Range & Mean \pm SD & Range & Mean \pm SD & T & P-value \\
\hline GCS & $10-15$ & $14.09 \pm 1.4$ & $8-15$ & $13.46 \pm 2.02$ & 2.956 & $0.003^{*}$ \\
\hline HR $($ beats/minute) & $60-95$ & $78.08 \pm 7.98$ & $50-140$ & $100.94 \pm 25.11$ & -9.508 & $0.000^{*}$ \\
\hline SBP $(\mathrm{mmHg})$ & $80-140$ & $113.33 \pm 10.91$ & $80-170$ & $112 \pm 20.16$ & 0.651 & 0.516 \\
\hline DBP $(\mathrm{mmHg})$ & $50-90$ & $73.85 \pm 8.39$ & $40-120$ & $72.18 \pm 17.86$ & 0.936 & 0.350 \\
\hline RR $($ cycle/minute) & $16-35$ & $20.7 \pm 3.44$ & $14-50$ & $21.96 \pm 5.22$ & & $0.024 *$ \\
\hline Temperature $\left({ }^{\circ} \mathrm{C}\right)$ & $36-38$ & $37.02 \pm 0.35$ & $36-38$ & $37.07 \pm 0.36$ & -1.165 & 0.245 \\
\hline
\end{tabular}

GCS: Galasgow Coma Scale; HR: Heart Rate; SBP: Systolic Blood Pressure; DBP: Diastolic Blood Pressure; RR: Respiratory Rate; Temp: Temperature; SD: Standard Deviation; * statistically significant $(P-$ value $<0.05)$

Table 2b: Degree of GCS among patients (282) with and without ECG changes.

\begin{tabular}{|c|c|c|}
\hline GCS & $\begin{array}{c}\text { Patients without ECG changes } \\
(\mathbf{n}=\mathbf{1 1 7}) \mathbf{( n ,} \boldsymbol{\%})\end{array}$ & $\begin{array}{c}\text { Patients with ECG changes } \\
(\mathbf{n}=\mathbf{1 6 5})(\mathbf{n}, \boldsymbol{\%})\end{array}$ \\
\hline Minor, GCS $\geq 13$ & $96(82.05)$ & $30(18.1)$ \\
\hline Moderate, GCS $9-12$ & $18(15.38)$ & $102(61.8)$ \\
\hline Severe, with GCS $\leq 8$ & $3(2.56)$ & $33(20)$ \\
\hline
\end{tabular}

Table 3: The relationship between poison with ECG changes and serum electrolyte disturbances

\begin{tabular}{|c|c|c|c|c|}
\hline $\begin{array}{c}\text { Poison with ECG } \\
\text { changes }\end{array}$ & Electrolyte disturbance & $\begin{array}{c}\text { Range (Na \& } K \text { in } m E q / L ; C a \text { in } \\
m g / d L)\end{array}$ & Mean \pm SD & N (\%) \\
\hline Organophosphate & $\begin{array}{l}\text { Hypernatremia \& } \\
\text { hypokalemia }\end{array}$ & $\begin{array}{l}\mathrm{Na}: 152-158 \\
\mathrm{~K}: 3.0-3.4\end{array}$ & \begin{tabular}{|c|}
$154.75 \pm 2.86$ \\
$3.19 \pm .13$
\end{tabular} & $12(24.49)$ \\
\hline Theophylline & $\begin{array}{l}\text { Hypokalemia \& } \\
\text { hypercalcemia }\end{array}$ & $\begin{array}{l}\text { K: } 3.1-3.4 \\
\text { Ca: } 10.5-10-9\end{array}$ & $\begin{array}{c}3.11 \pm 0.29 \\
10.73 \pm 0.17\end{array}$ & $28(9.93)$ \\
\hline Antipsychoyic & Hyponatremia & $\mathrm{Na}: 129-132$ & $130.50 \pm 1.29$ & $4(66.66)$ \\
\hline Antihypertensive & $\begin{array}{l}\text { Hyponatremia, } \\
\text { hypokalemia \& } \\
\text { hypocalcemia }\end{array}$ & $\begin{array}{l}\text { Na: } 129-133 \\
\text { K: } 3.1-3.4 \\
\text { Ca: } 8.1-7.9 \\
\end{array}$ & $\begin{array}{c}130.7 \pm 1.37 \\
3.21 \pm .1197 \\
7.95 \pm .108 \\
\end{array}$ & $10(28.57)$ \\
\hline Digitalis & Hyperkalemia & K: 5.4-5.6 & $5.483 \pm .075$ & $6(60)$ \\
\hline Cyclic antidepressant & Hyponatremia & $\mathrm{Na}: 128-133$ & $130.30 \pm 1.49$ & $12(92.31)$ \\
\hline B- blocker & $\begin{array}{l}\text { Hyponatremia \& } \\
\text { hyperkalemia }\end{array}$ & $\begin{array}{l}\mathrm{Na}: 130-131 \\
\mathrm{~K}: 5.4-5.5 \\
\end{array}$ & \begin{tabular}{|c|}
$130.50 \pm 0.707$ \\
$5.5 \pm 0.05$ \\
\end{tabular} & $2(50)$ \\
\hline SSRI & Hyponatremia & $\mathrm{Na}: 130$ & - & $1(25)$ \\
\hline Valproic acid & $\begin{array}{l}\text { Hypernatremia \& } \\
\text { hypocalcemia }\end{array}$ & $\begin{array}{l}\text { Na: } 154-155 \\
7.9-8.1\end{array}$ & $\begin{array}{c}154.50 \pm .707 \\
7.95 \pm .07 \\
\end{array}$ & $2(50)$ \\
\hline
\end{tabular}

$N=$ number. $N B:$ normal serum level of $N a(135-145 \mathrm{mEq} / \mathrm{L}), \mathrm{K}(3.5-5.5 \mathrm{mEq} / \mathrm{L})$ \& total Ca $(9-10.5 \mathrm{mg} / \mathrm{dL})$ 
Table 4: ECG findings encountered among patients with ECG changes (165 patients).

\begin{tabular}{|l|c|c|l|l|}
\hline \multicolumn{1}{|c|}{ Type of change } & $\mathbf{N}$ & $\mathbf{\%}$ & \multicolumn{1}{|c|}{ Poisons associated with this change } \\
\hline Sinus tachycardia & 122 & 73.94 & $\begin{array}{l}\text { OPC, theophylline, CAs, CBZ, antihypertensive, CO, antipsychotic, zinc } \\
\text { phosphide, BDZs, levothyroxine, corrosive, salbutamol, tramadol, salicylate, } \\
\text { valproic acid and dexamethasone }\end{array}$ \\
\hline Sinus bradycardia & 19 & 11.51 & OPC, digitalis, anti- migraine, $\beta$ - blockers and heroin \\
\hline Sinus dysrhythmia & 9 & 5.45 & Digitalis, OPC, $\beta$ - blockers and SSRIs \\
\hline Nodal rhythm & 4 & 2.42 & OPC and zinc phosphide \\
\hline Nodal tachycardia & 1 & 0.61 & Digitalis \\
\hline Atrial flutter & 2 & 1.21 & Digitalis \\
\hline Atrial Fibrillation (AF) & 2 & 1.21 & OPC \\
\hline $\begin{array}{l}\text { Prolonged PR } \\
\text { (1 }\end{array}$ & 10 & 6.06 & Digitalis, Antiarrhythmic Ic, Antihistaminic \\
\hline $\begin{array}{l}\text { Scoping ST segment } \\
\text { (digitalis effect) }\end{array}$ & 5 & 3.03 & Digitalis \\
\hline Upsloping ST segment & 4 & 2.42 & Theophylline \\
\hline $\begin{array}{l}\text { Abnormal T wave } \\
\text { (biphasic or inverted) }\end{array}$ & 12 & 7.27 & Digitalis, theophylline, antihypertensive and zinc phosphide \\
\hline $\begin{array}{l}\text { Prolonged QTc } \\
\text { interval }\end{array}$ & 36 & 21.82 & Theophylline, OPC, Antipsychotic, CAs, CBZ, levothyroxine and Tramadol \\
$\begin{array}{l}\text { N: number; OPCs: organophosphorus compounds; CAs: cyclic antidepressant; CBZ: carbamazepine; CO: carbon } \\
\text { monoxide; BDZ: benzodiazepine; SSRIs: selective serotonin reuptake inhibitors. }\end{array}$ \\
\hline
\end{tabular}

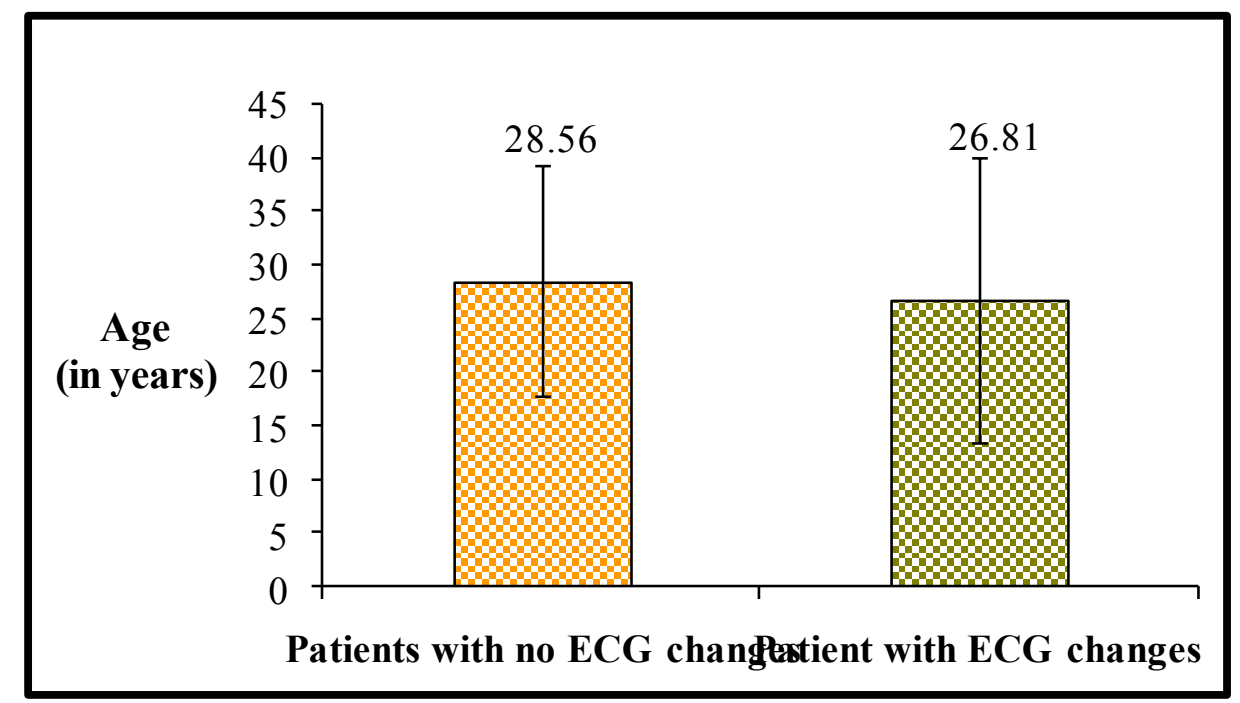

Fig 1: Mean age distribution among patients with and without ECG changes.

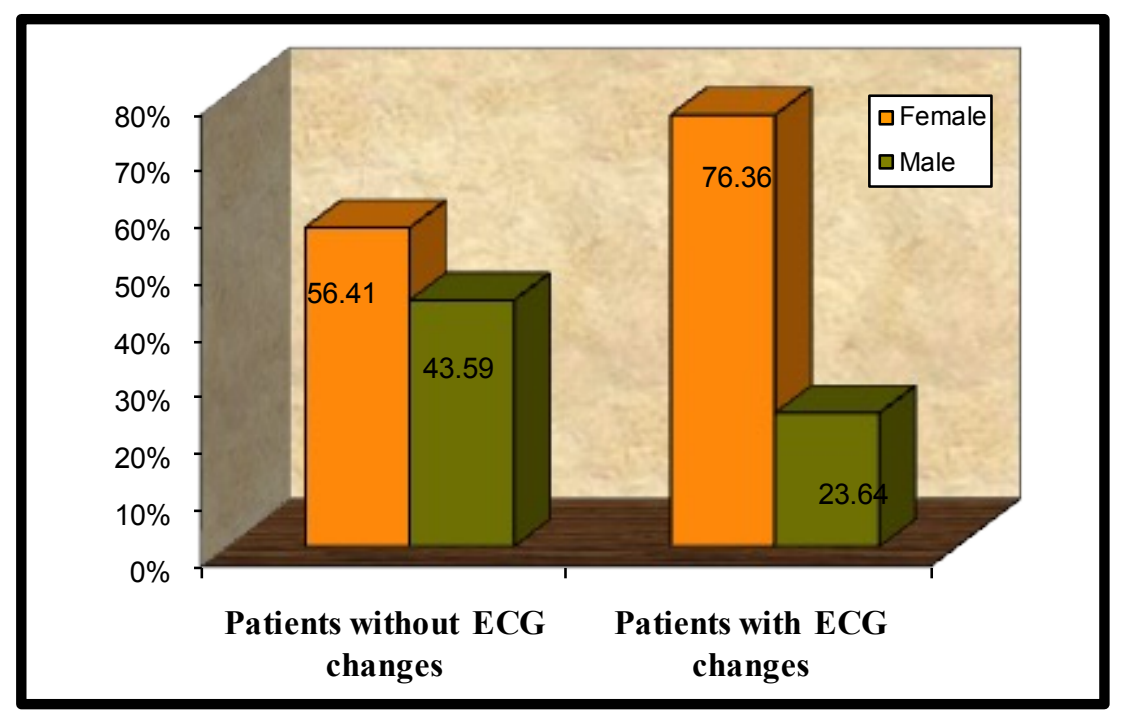

Fig 2: Gender distribution among patients with and without ECG changes. 


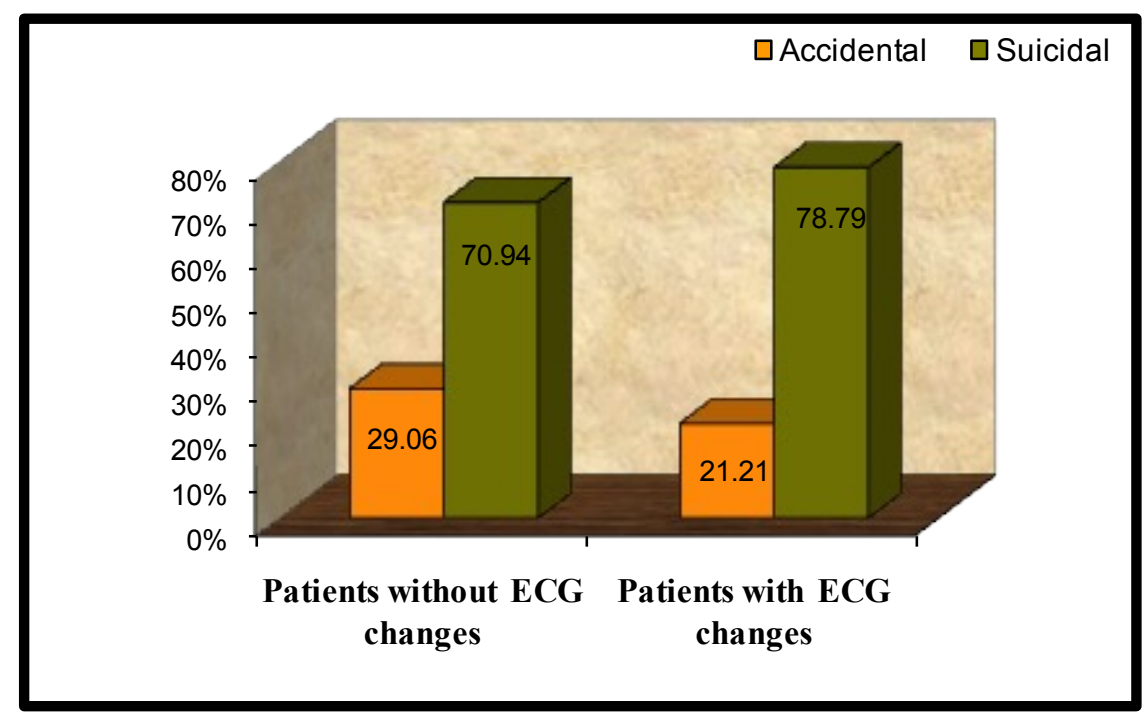

Fig 3: Circumstances of poisoning among patients with and without ECG changes.

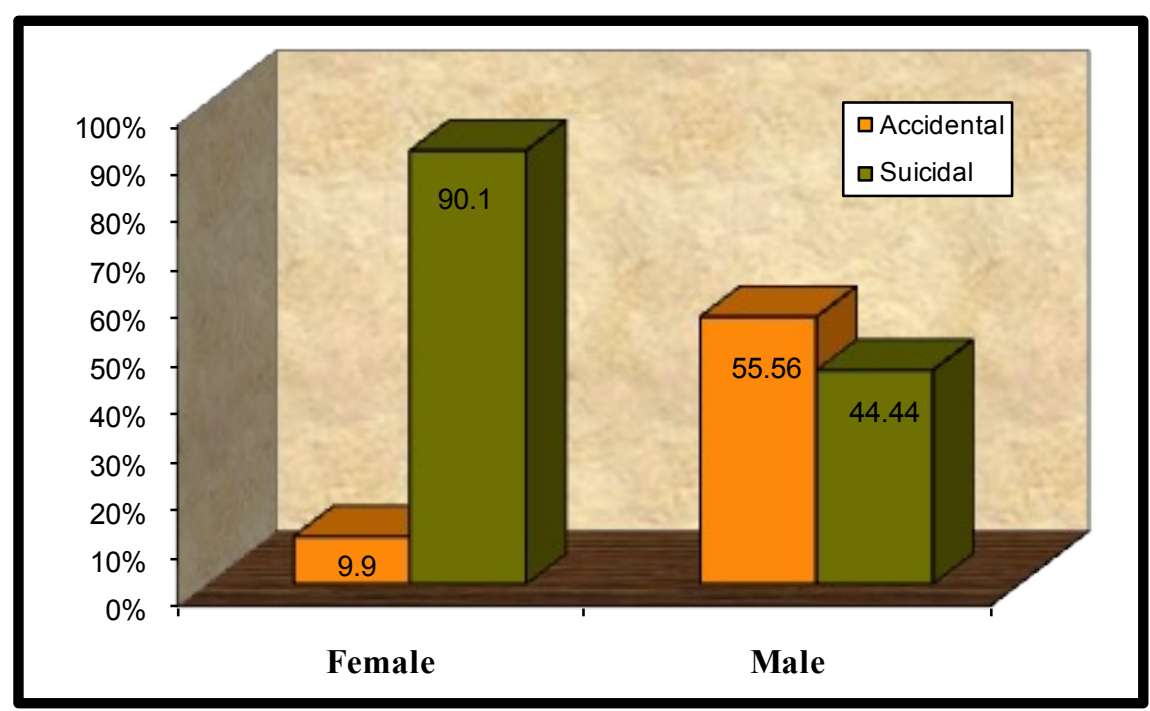

Fig 4: Circumstances of poisoning among both genders.

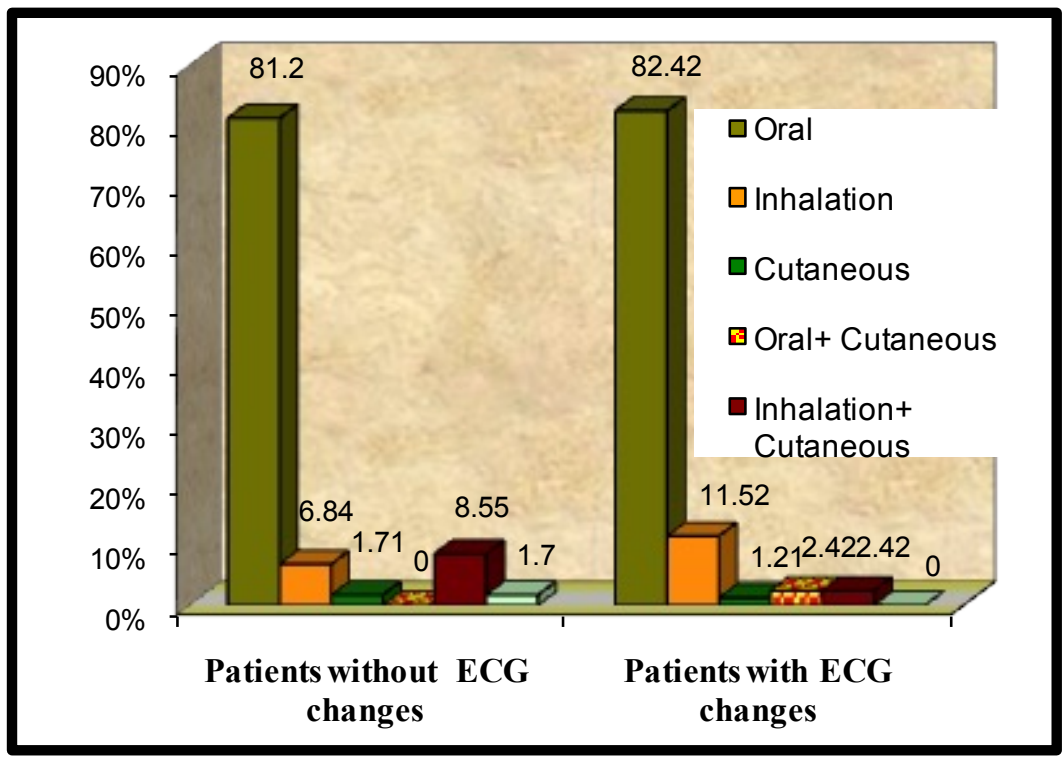

Fig 5: Route of intake among patients with and without ECG changes. 


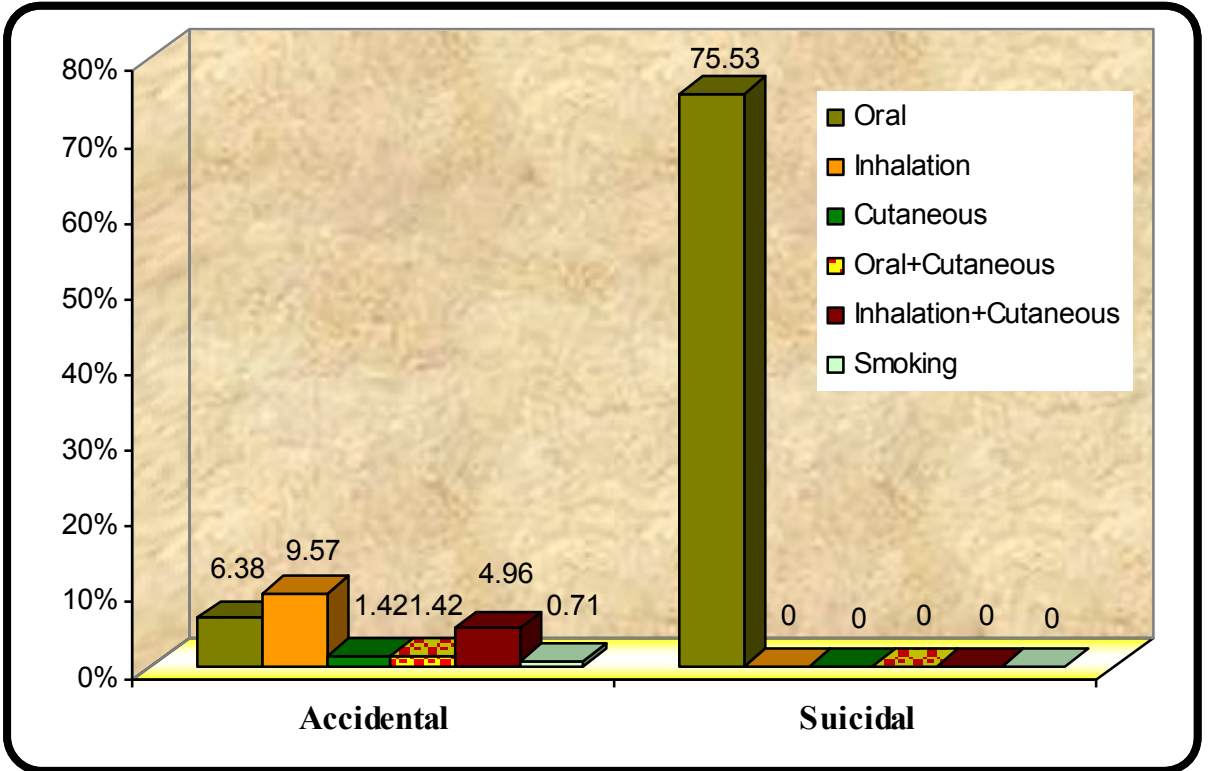

Fig 6: Correlation between circumstances of poisoning and route of intake among the studied patients.

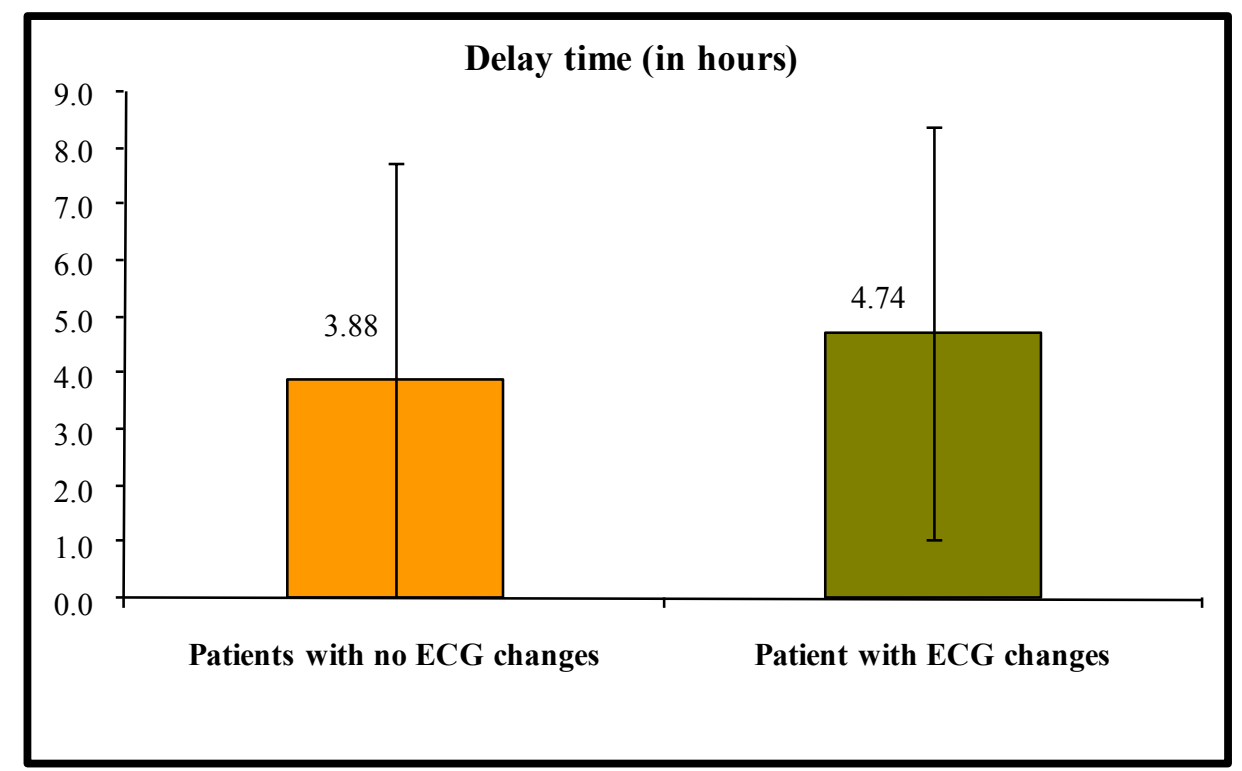

Fig 7: The mean delay time (in hours) among patients with and without ECG changes.

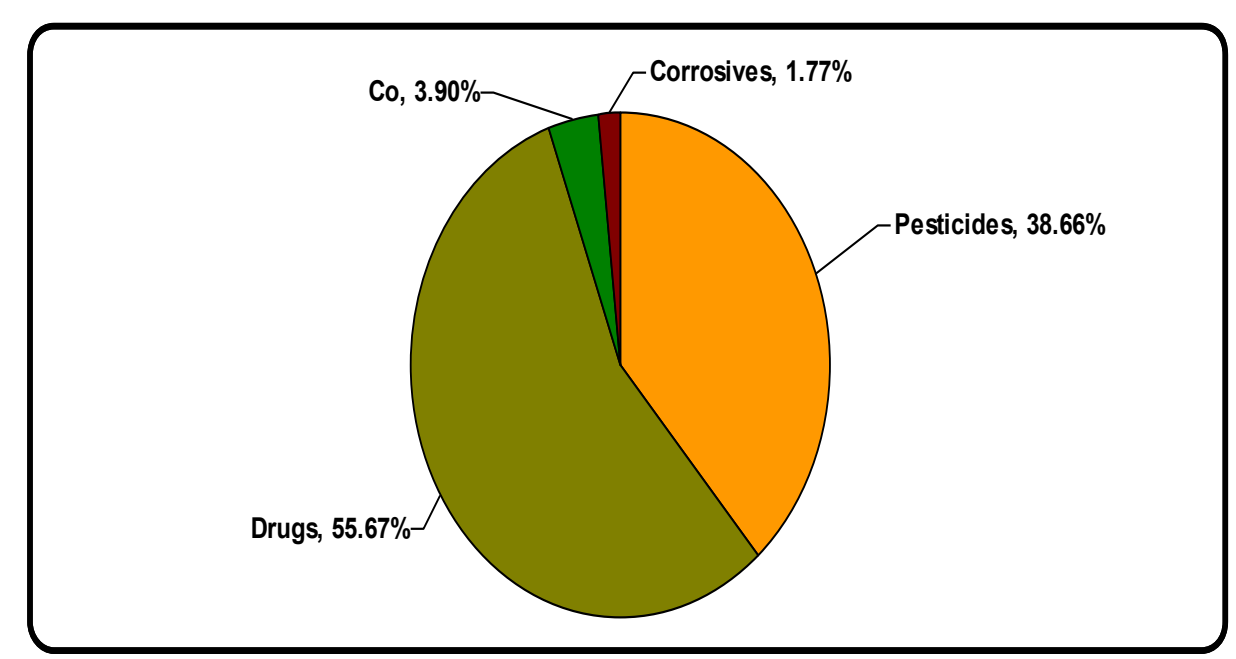

Fig. 8: The incidence of poison categories in the present study. 


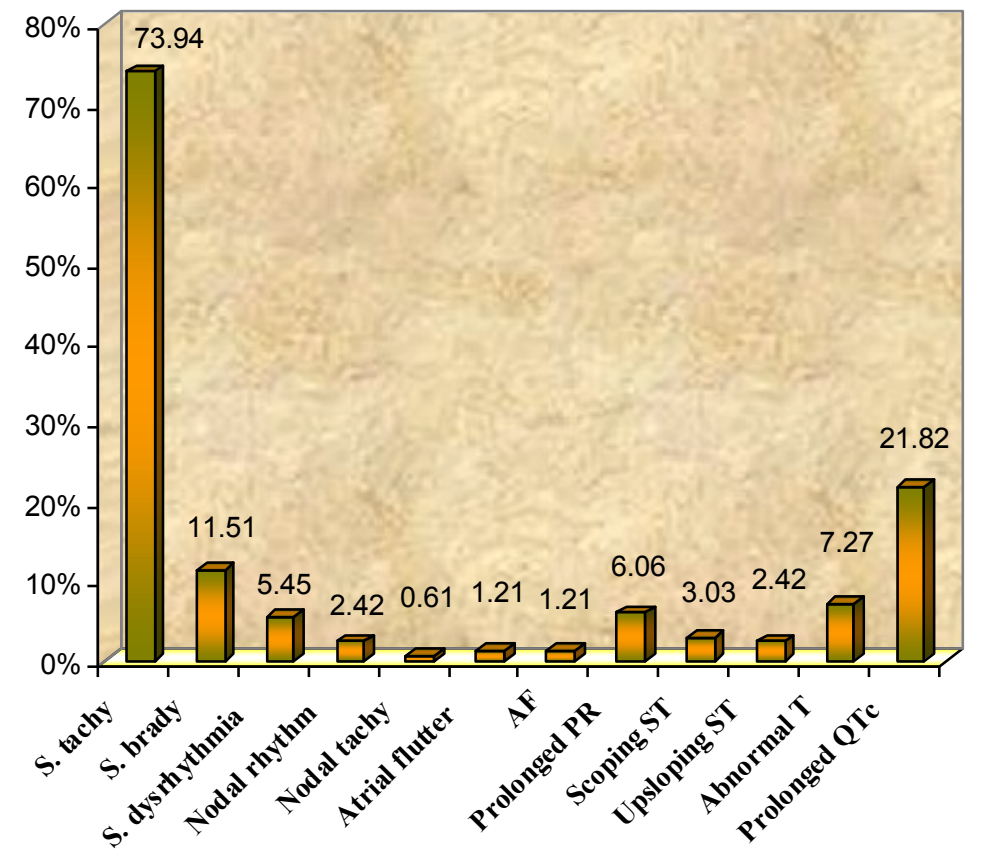

Fig 9: ECG finding encountered among patients with ECG changes.

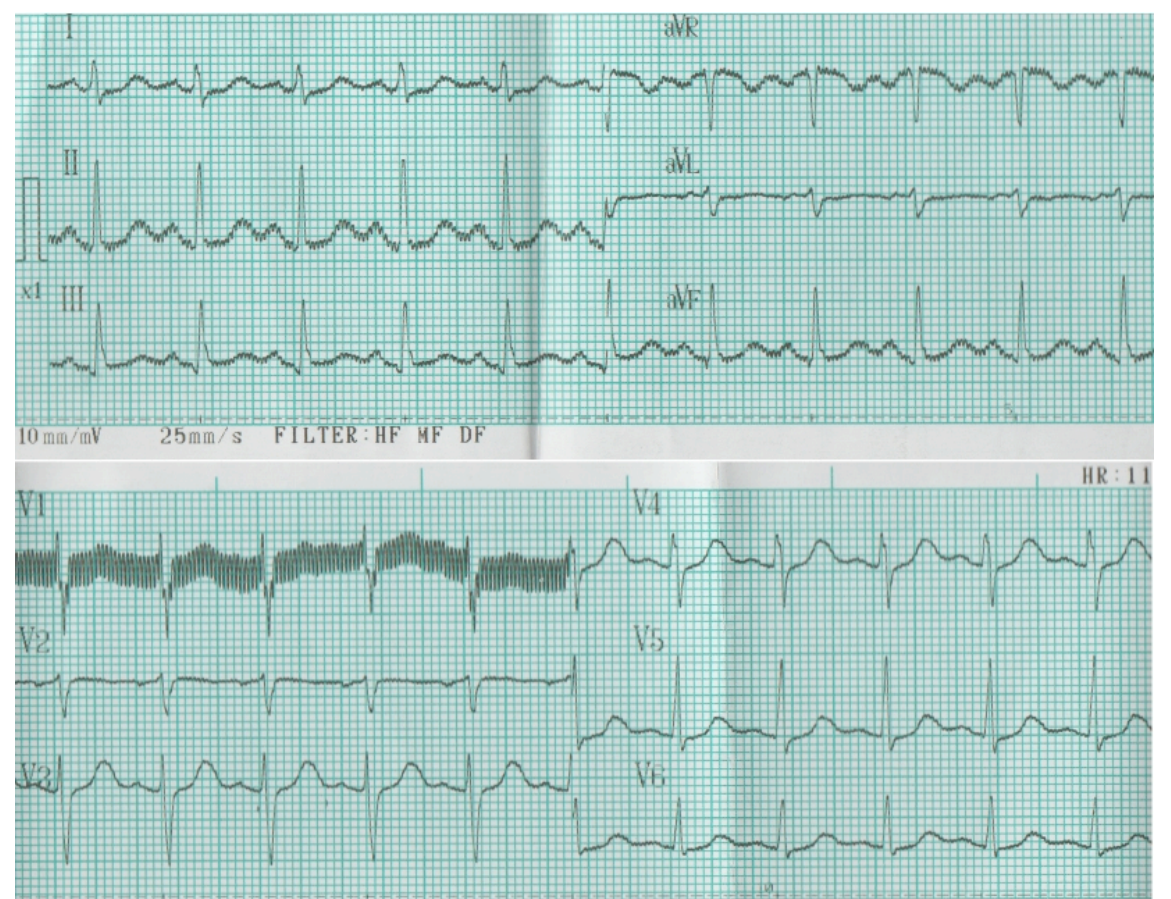

Fig 10: An ECG from a female patient (aged 18 years) with attempted suicidal poisoning with theophylline showing sinus tachycardia (rate $=120$ beat/ minute, regular) and prolonged QTc interval

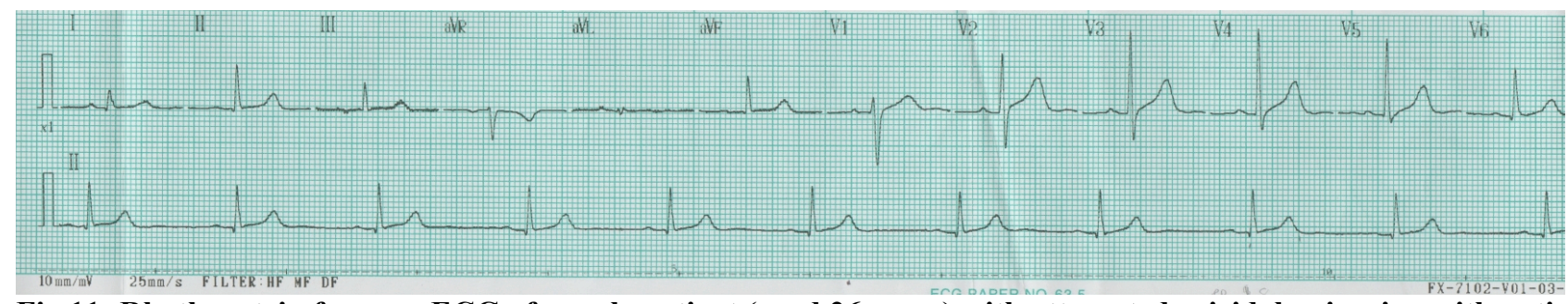

Fig 11: Rhythm strip from an ECG of a male patient (aged 26 years) with attempted suicidal poisoning with antimigraine drug showing sinus bradycardia (rate $=55$ beat/ minute, regular). 


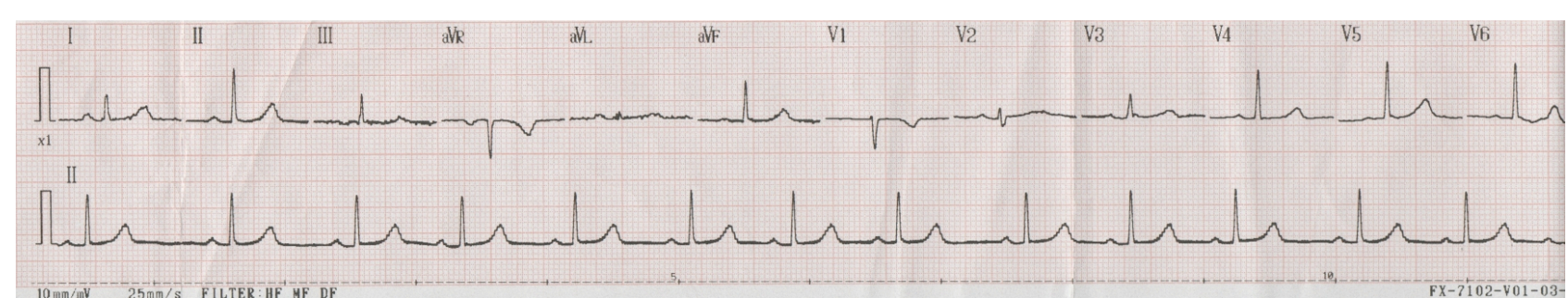

Fig 12: Rhythm strip from an ECG of a female patient (aged 18 years) with attempted suicidal poisoning with $\beta$ blocker showing sinus dysrhythmia (rate $=60$ beat/ minute, irregular).

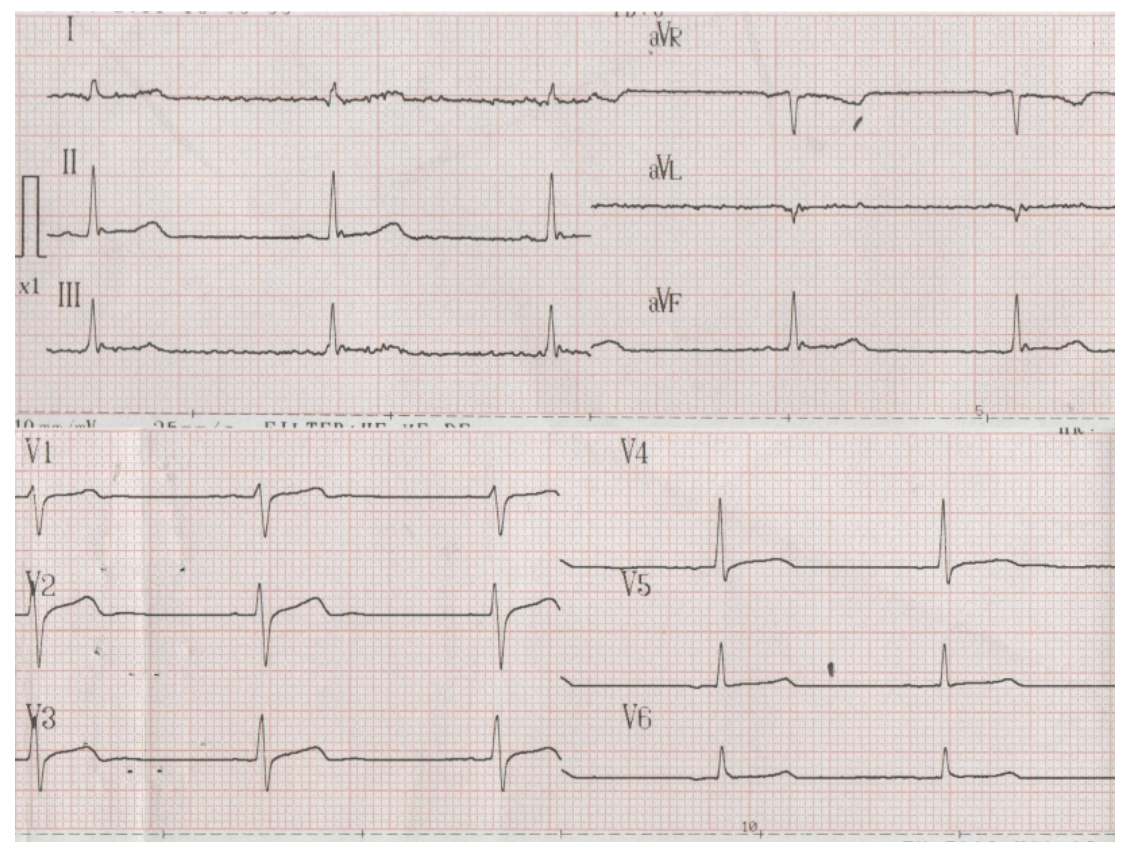

Fig 13: An ECG from a male patient (aged 23 years) with accidental organophosphorus poisoning showing nodal rhythm (rate $=50$ beat/ minute, regular).

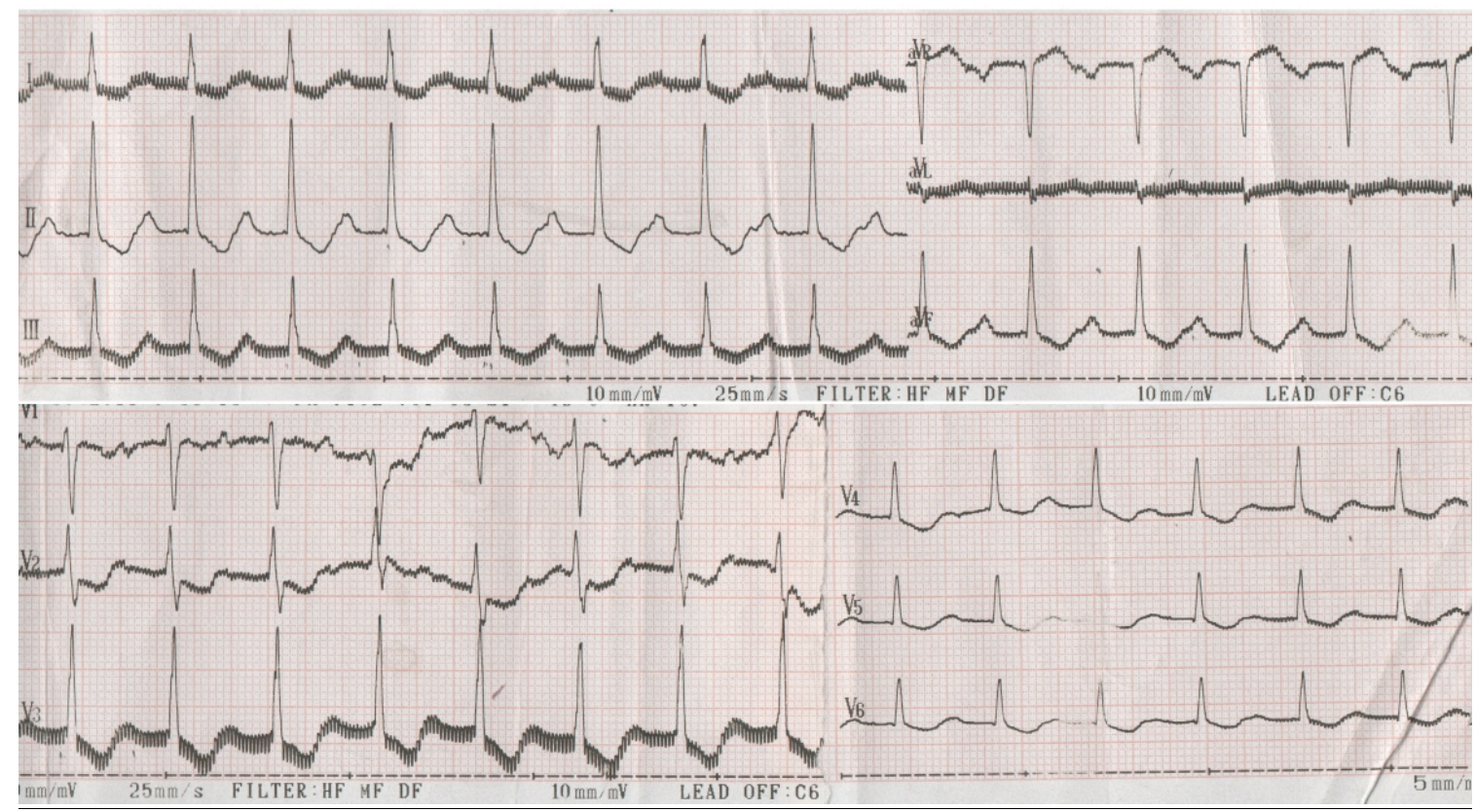

Fig 14: An ECG from a female patient (aged 18 years) with attempted suicidal poisoning with digitalis showing nodal tachycardia (rate $=110$ beat $/$ minute, regular), scoping ST segment and biphasic $\mathrm{T}$ wave. 


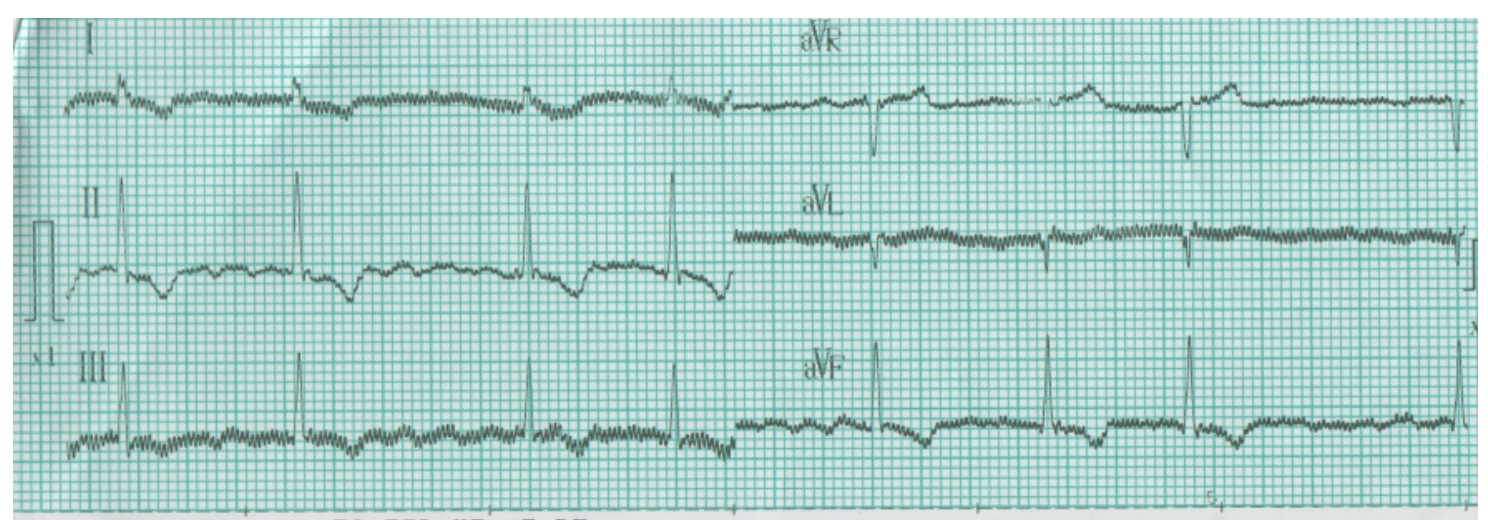

$10 \mathrm{~mm} / \mathrm{mV} \quad 25 \mathrm{~mm} / \mathrm{s} \quad$ FILTER:HF $M F \quad$ DF

Fig 15: An ECG from a female patient (aged 33 years) with attempted suicidal poisoning with digitalis showing atrial flutter (rate $=70$ beat/ minute, irregular), scoping ST segment \& $T$ wave inversion.

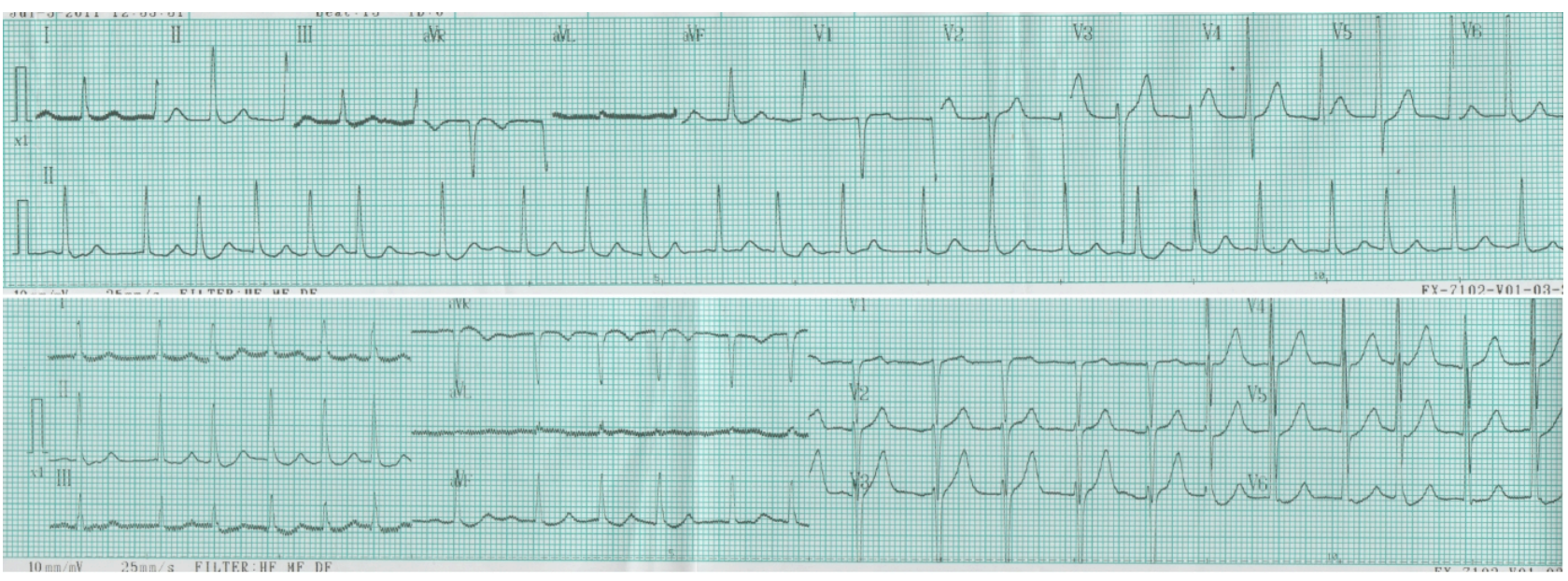

Fig. (16): An ECG from a male patient (aged 50 years) with accidental organophosphorus poisoning showing atrial fibrillation (rate $=115$ beat $/$ minute, irregular).

\section{Discussion}

The ECG is ubiquitous in ED and intensive care units. It is a valuable diagnostic tool for patients with acute cardiovascular complaints (Clancy, 2006). Most of patients were in the age group between 18 and 29 years (67.02\% of all patients), followed by age group between 30 and 39 years (19.86\% of all patients). This was in partial agreement with Akbaba et al. (2007), who reported that the average age of their study patients was 25.2 years (ranged from 14 to 80 years). Sixty and half percent of them were in the age group from 15 to 24 years and $25.9 \%$ were between 25 and 34 years. On the other hand the results of the current study disagreed with Marahatta et al. (2009) who found that most poisoning cases occurred in the age group of above 40 years. This difference could be explained by the information that the number of patients in their study was small (54 cases) and this might give false results. Furthermore, in this study, $31.91 \%$ were males and $68.09 \%$ were females. This was in agreement with Gülğolu and Kara (2005), who reported that $25.9 \%$ of their study patients were males and $74.1 \%$ of them were females. On contrary, these results disagreed with results obtained by Singh and Unnikrishnan (2006), as they found that males were $70.5 \%$ and females were $29.5 \%$ of their study patients. They attributed the male preponderance in their study to the fact that males are more exposed to occupational hazards, and stress or strain as compared to females in this part of the world (South India). While in the current study, the female preponderance may be due to higher rate of psychological stress in young women and their tendency to prefer suicide attempt as a way of salvation.

In this study, suicidal attempts occurred in $75.53 \%$ of patients and mainly in females $(90 \%$ of females) while accidental poisoning occurred in 24.47 $\%$. This was nearly similar to result obtained by Akbaba et al. (2007), as $87 \%$ of poisoning cases in their study were suicidal attempts while only $13 \%$ were unintentional. On the other hand Sawalha et al. (2010) reported unintentional poisoning in $92 \%$ of cases, with significant association between circumstances of poisoning and gender. Females have more intentional poisoning than males $(64.8 \%$ for females versus $35.2 \%$ for males). The increased number of suicidal attempts in the present study may be due to many factors such as poverty, financial problems, unemployment, marital conflicts, break-up in the family support system and stress due to exams among the students.

In the present study, the most common route of poisoning was the oral $(81.91 \%)$ of patients. This was followed by inhalation $(9.57 \%)$, then the 
cutaneous exposure $(1.42 \%)$. The rest of patients were exposed via combined routes and smoking. These data coincided with data obtained by Ayoğlu et al. (2009). They found that poisons were taken mainly by ingestion $(87.8 \%)$, followed by inhalation $(11.9 \%)$, then the combined oral and inhalation $(0.3 \%)$. In contrast Sawalha et al. (2010) reported that the route of poisoning in their study was mainly through bites and stings $(72.3 \%)$ followed by oral route $(23.5 \%)$ then inhalation (3.4\%). This difference may be explained by the geographic nature of the region, and by the difference in the nature of poisons included in their study and the present study (as the route of intake differs according to the nature of poison). In addition the difference in the circumstances of poisoning between both studies may affect the route of intake.

Toxins included in the current study were divided into 4 groups; therapeutic drugs, followed by pesticides then $\mathrm{Co}$ and lastly corrosives. Among therapeutic drugs, the most common was theophylline then antipsychotic drugs. While among pesticides, the most common was organophosphorus compounds followed by Zinc phosphide. These results were in agreement with Akbaba et al. (2007), who reported that the frequency of toxins in their study was as follows: therapeutic drugs $(71.1 \%)$, followed by pesticides $(18.9 \%)$, caustics $(3.1 \%)$, Co $(1.8 \%)$, foods $(3.7 \%)$ and lastly alcohol in $1.45 \%$ of their studied patients. On the other hand, these results disagreed with those of Jaiprakash et al. (2011), as they found that poisoning with organophosphorous and organochloride compounds was the most common $(60 \%)$ followed by aluminum and zinc phosphide (22\%). Drugs were consumed by the rest of cases (among which phenobarbitone was the commonest). The prevalence of poisoning with drugs in the current study could be explained by the fact that in Egypt, drugs could be easily purchased from pharmacies without prescription. Also the high incidence of pesticides toxicity was due to their wide use in agriculture and hence their easy accessibility.

In this study $58.51 \%$ of patients had ECG changes. These were: sinus tachycardia followed by prolonged QTc interval then sinus bradycardia and lastly nodal tachycardia. It was obvious that sometimes two or more changes were present in the same patient. These results partially coincided with results obtained by Wells et al. (2008) from their study for the association of cardiovascular toxins with ECG abnormality in poisoned patients. They reported that 70 $\%$ of patients had an ECG abnormality. Sinus tachycardia was the most common change encountered (47\%), followed by abnormal QRS configuration and widening then QT interval prolongation. In contrast, the results of the present study statistically disagreed with results obtained by Aly et al. (2009), as they reported that among their study patients only $22 \%$ showed ECG changes. These changes mainly included sinus tachycardia $(59.62 \%)$, sinus bradycardia $(32.7$ $\%)$, and then atrial fibrillation (1.9\%).

Moreover, the delay time ranged between half an hour to 19 hours with a mean of 4.3 hours. While, the delay time ranged from half an hour to 36 hours with a mean of 3.6 hours in the study performed by Aly et al. (2009). The longer mean time in the present study may be attributed to the fact that $75.53 \%$ of cases were intentional so they were not willing to ask for a rescue or they were intending to hide the act. A relationship between the delay time and the occurrence of ECG changes was found. It could be concluded that most types of ECG changes occurred in patients with delay time more than 2 hours. This may be explained by delayed beginning of the treatment which leaded to increase in the initial peak blood level of poison that may induce irreversible tissue damage (George et al., 2004). But it is to be considered that other factors might affect this relationship such as the amount of poison that was ingested (which was an unavailable data in this study) and also personal variations.

In the current study, acidosis was detected in the following poisons overdoses OP, theophilline, Co, tramadol and salicylate. Acidosis alters the electrical activity of cardiac muscle, having marked effects on most of the membrane currents and produces the following ECG changes: a marked decrease in heart rate and increases in $\mathrm{P}-\mathrm{R}$ interval. This increase in the $\mathrm{P}-\mathrm{R}$ interval could be due to an increased delay in the $\mathrm{AV}$ node, rather than a decrease in the rate of conduction of the action potential through the atria. Similarly, the marked decrease in heart rate observed during acidosis could be explained by a direct inhibitory effect of acidosis on the SA node. However, acidosis has little or no effect on the duration of QRS complex suggests that acidosis has little effect on the rate of propagation of the action potential (Aberra et al., 2001). In the present study, increases in $\mathrm{P}-\mathrm{R}$ interval were detected in the following poisons overdoses: digitalis, antiarrythmic Ic and antihistaminic. The explanation may be due to the mechanism of action of each poison -as it will be mentioned later- and not due to acidosis however, acidosis may be a cofactor for decrease in heart rate (sinus dradycardia) as detected in OP and tramadol overdoses.

Sinus tachycardia was detected in all patients with theophilline poisoning. This could be explained by the fact that methylxanthines, including theophylline, are cardiac stimulants that result in positive inotropy and chronotropy (Hoffman, 2006). Shannon, (1993) reported that sinus tachycardia was also present in all patients included in his study on theophilline poisoning.

The most common ECG abnormalities by antipsychotic drugs were prolonged QTc interval (22 $\%)$ and supraventricular tachycardia (including sinus tachycardia) in $22 \%$. The range of mechanisms whereby antipsychotic drugs can influence $\mathrm{CV}$ function is very broad and includes direct effects such as blockade of muscarinic receptors in the heart, blockade of $\alpha_{1}$-adrenoceptors, blockade of sodium, potassium channels and calcium channels and blockade of calmodulin which may result in protein degradation causing structural damage and toxic cardiomyopathy. 
There are also indirect effects through blockade of $\alpha_{2}$ adrenoceptors in the CNS (Buckley and Sanders 2000). Sinus tachycardia was present in all antihypertensive drugs overdosed patients. This might be a reflex response for hypotension in some patients or caused by stress associated with cases of poisoning in other patients (Richardson et al., 2007). They also, reported that toxicity of loop diuretics (including furosemide) lead to hyponatremia, hypokalemia, hypocalcemia, hypomagnesemia, and fluid depletion.

The most common change encountered among digitalis poisoning was prolonged $1^{\text {st }}$ degree heart block (present in 6 patients, $54.55 \%$ ), followed by digitalis effect (scoping of ST segment) in 5 (45.45\%), $\mathrm{T}$ wave abnormality in $5(45.45 \%)$, sinus dysrhythmia in $4(36.36 \%)$ then sinus bradycardia in $2(18.18 \%)$ and nodal tachycardia in $1(9.09 \%)$. These results are nearly similar to results of Bassioni et al. (1997), in a study on 20 patients. On the other hand, Lin et al. (2010) reported an outbreak of foxglove leaf poisoning including sinus bradycardia and ventricular premature contraction. These dysrhythmias result from the complex electrophysiologic influences on myocardium and conduction system of the heart resulting from direct, vagotonic, autonomic actions, increased automaticity and excitability of these cardioactive steroids. (Hack and Lewin 2006).

Sinus tachycardia was present in all cyclic antidepressant overdosed patients, while prolonged QTc interval was present in 4 only $(33.33 \%)$. These results were different from the results obtained by Phillips et al. (1997), as they reported that QTc prolongation was the most common change encountered in their study $(76.1 \%)$ followed by tachycardia (49.2\%) then QRS prolongation (35.7\%). This difference might be due to different doses or formulas among both studies. Sinus tachycardia primarily results from peripheral muscarinic antagonism and norepinephrine reuptake inhibition, while, QTc interval prolongation results primarily from slowed depolarization as they block the rapid inward movement of sodium ions into the fast sodium channel (Liebelt, 1997).

Sinus tachycardia was detected in all CBZ overdosed patients and prolonged QTc interval (in 4 patients only). These results disagreed with results obtained by Apfelbaum et al. (1995), who carried a study including 42 adults with acute ingestion of CBZ, ECG changes included prolonged QTc interval in 50 $\%$, sinus tachycardia in $27 \%$, and prolonged QRS interval in $11 \%$. These differences might be explained by unequal number of patients in both studies. In addition, different doses of any drug give different effects.

Sinus tachycardia occurs in all CBZ overdosed patients as a result of an anti-cholinergic mechanism, hypotension with myocardial depression, and cardiac conduction abnormalities while prolongation of QT interval occurs because CBZ may cause depression of phases 0,2 , and 4 of the action potential in cardiac tissue (Doyon, 2006).
In $\beta$ - blocker toxicity, sinus bradycardia was detected in 2 patients, while sinus dysrhythmia was present in 2 patients. These results were different from results of the study done by Love et al. (2002), on 13 patients where, prolonged PR interval was detected in 10 patients, 8 patients with prolonged QRS, 3 patients with sinus bradycardia, 3 patients with prolonged QTc, and 1 patient with AF. Anderson, (2008) reviewed the causes of ECG changes associated with $\beta$-blocker toxicity. He reported that significant blockade of $\beta_{1}$ receptors in the SA node decreases automaticity causing sinus bradycardia and Inhibition of the conducting system most commonly causes AV block.

As regards organophosphate poisoning, ECG abnormalities were present in $50.52 \%$ of the cases. The most common ECG changes were sinus tachycardia followed by sinus bradycardia then prolonged QTc interval. The results of the present study almost coincided with results obtained by Karki et al. (2004), and Abdelwahab et al. (2005), who reported that Sinus tachycardia was the most common ECG abnormalities. Other common findings in Karki et al. (2004), study were prolonged QTc interval in 37.8 $\%$ and sinus bradycardia in $18.9 \%$.

The mechanism by which organophosphates induce cardiotoxicity is still uncertain. Three phases of cardiac toxicity after organophosphate poisoning were described: phase 1, is a brief period of increased sympathetic tone; phase 2 , is a prolonged period of parasympathetic activity; and in phase 3, Q-T prolongation is followed by torsade de pointes ventricular tachycardia, and then ventricular fibrillation (Ludomirsky et al., 1982 and Karki et al., 2004).

In the current study theophylline causes elevation of serum calcium level, similar result is obtained by McPherson et al. (1986), as they found eleven patients out of sixty had hypercalcemia while, serum calcium levels fell significantly in three additional patients in the same study. Theophylline toxicity causes hypercalcemia by a system subject to beta-adrenergic regulation (McPherson et al., 1986).

Hyponatremia is the electrolytic disorder most commonly observed among general hospitalized populations, being found in $2 \%$ of hospitalized patients (Kris et al., 2002). In this study, hyponatremia was detected in patients overdosed with antipsychotics, cyclic antidepressants, SSRI, antihypertensive, and Bblockers. Hyponatraemia is known to occur as a rare event but clinically important with different overdoses of diuretics, psychotropic drugs including newer atypical and older typical drugs (Meulendijks et al., 2010), antidepressant (Pereira et al., 2008), selective serotonin reuptake inhibitors (Mannesse et al., 2010) and antiepileptic drugs (carbamazepine) (Krysiak and Okopie, 2007).

Hyponatraemia also, may be due to the chronic psychiatric disorder itself (Thomas and Verbalis, 1995). The mechanism by which these drugs induce hyponatraemia is still unclear. It is generally thought that these drugs stimulate $\mathrm{ADH}$ release in the brain (Madhusoodanan et al., 2002) and/or enhance of 
the activity of ADH on the kidney, leading to the syndrome of inappropriate antidiuretic hormone secretion (SIADH) (Thomas and Verbalis, 1995). Also, hyponatremia was detected in this study in patients with antihypertensive drugs overdose (diuretics and angiotensin converting enzyme inhibitors). Angiotensin converting enzyme inhibitors, calcium channel blockers, and -adrenoceptor blockers are risk factors for the development of hyponatraemia as showed in the study done by (Siegler et al., 1995). Diurtics are also, a common cause of hypokalemia and hypomagnesemia which may predispose to ventricular tachyarrythmia (Sonnenblick et al., 1993).

Marar and Amico (1998) found that use of fluoxetine and tricyclic antidepressants (TCAs) was significantly associated with hyponatraemia, with fluoxetine showing a higher risk than TCAs.

In the current study, valporoic acid overdose (VPA) overdose revealed electrolyte abnormalities that included hypernatremia and hypocalcemia. This is consistent with the result described by Marklund et al. (2007). VPA toxicity causes hypernatremia since it is a sodium salt $(\mathrm{Na}+$ present in the VPA preparation). The fact that $100 \mathrm{mg}$ VPA contains an estimated 13.2 $\mathrm{mg}$ of $\mathrm{Na}+$ likely explains the observed hypernatremia. Also, valproic acid is not an enzymatic (cytochrome P450) inducer, nor it interferes with Vitamin D metabolism. However its metabolites act as anions, thus, binding plasma calcium ions and for this reason may cause hypocalcemia (Thomas and Verbalis, 1995). Its effects are dose- and time-dependent. The mechanism involved in such alteration is still matter of open debate (Vucicevic et al., 2007; Lheureux and Hantson, 2009)

While, hypernatremia and hypokalemia were detected in the current study in OP compound intoxication. These were mostly due to dehydration associated with them. These result was in agreement with the study performed by Rivera and Rivera (1990). In addition they detected other laboratory abnormalities of leukocytosis and hyperglycemia.

Isolated hypernatremia or hyponatremia has no consistent effect on the ECG, hypernatremia shortens the QRS duration while, hyponatremia prolongs it (Clancy 2006) .

In the current study hyperkalemia was detected in digitalis and B-blokers overdose. The hyperkalemia due to dgitalis is consistent with the result obtained by Thacker and Sharma (2007). When digoxin's mechanism kicks-in, then it decreases the use of $\mathrm{K}+$ ions in the sodium-potassium pump by decreasing the Na-K ATPase activity. This reduction leads to a build-up of potassium in the body. Dehydration and various illnesses often are also contributing factors to the change to $\mathrm{K}+$ levels and hyperkalemia. Hyperkalemia may be associated with acute renal failure that subsequently precipitates digoxin toxicity. Cardioactive steroid drug poisoning rarely produces hyperkalemic ECG changes (Bauman et al., 2006; Thacker and Sharma, 2007).

Hyperkalemia due to B-blokers overdose was detected by Ede et al. (1997). Beta blockade, especially of the beta- 1 receptor at the macula densa inhibits renin release, thus decreasing the release of aldosterone. This causes hyponatremia, hyperkalemia and water retention (Baldasseroni et al., 2011).

\section{Conclusion}

Poisons associated with ECG changes account for 58.5 $\%$ of patients included in this study and affect mainly middle age group (this may affect the productivity of the society). Organophosphorus compounds were responsible for the highest incidence of ECG changes of most cases of intoxication (34.4\%). This was followed by theophylline (9.93). Sinus tachycardia was the most common ECG changes (73.94\%) among patients with acute poisoning which might be explained by different mechanism of poisons, but sometimes it was simply related to pain or stress associated with acute poisoning. This is followed by prolonged QTc interval $(21.82 \%)$ and sinus bradycardia (11.51\%).

\section{Recommendations}

Public health education about the hazards of poisons and how to deal with cases of acute poisoning are a must. Strict regulation should be taken as regard dispensing of drugs without prescription. Programs to reduce the availability, sailing, and dealing with pesticides must be set up, also regulatory control aiming to substitute pesticides with safer, less toxic ones. Psychiatric treatment is necessary for any patient who recovers from a suicidal attempt with emphasis on the concept that all religions forbid suicide. Performing an ECG for every patient with acute poisoning as this could help in early recognizing the possible cardiotoxicity by a relatively simple and non invasive tool. Further work to study the relationship between each poison and the occurrence of ECG changes on a large scale of patients is recommended in order to evaluate the validity of this simple tool in predicting cardiotoxicity and affecting treatment.

\section{Reference}

Abdelwahab WA, Elkolaly HR, Salaheldin RM et al., (2005): "A study of cardiac manifestations of acute poisoning with organophosphate and carbamate compounds". M. SC Thesis at Faculty of Medicine, Ain Shams University.

Aberra A, Komukai K, Howarth FC et al., (2001): The effect of acidosis on the ECG of the rat heart. Experimental Physiology. 86.1, 27-31.

Akbaba M, Nazlican E, Demirhindi H et al., (2007): "Etiological and demographical characteristics of acute adult poisoning in Adana, Turkey". Hum Exp Toxicol. 26: 401- 406.

Akdur O, Durukan P, Ozkan S et al., (2010): "Poisoning severity score, Glasgow coma scale, corrected QT interval in acute organophosphate poisoning". Hum Exp Toxicol; 29(5): 419- 425. 
Aly WM, Abdelsalam HF, Helmy TA et al., (2009): "cardiovascular disturbances associated with acute poisoning among patients admitted to Alexandria poison center". M. SC Thesis at Faculty of Medicine, Alexandria University. Under supervision of Abdelsalam HF, Helmy TA and Megahed HM

Anderson AC (2008): "Management of BetaAdrenergic Blocker Poisoning". Clin Ped Emerg Med. 9:4-16.

Apfelbaum JD, Caravati EM, Kerns WP, Bossart PJ et al., (1995): "Cardiovascular Effects of Carbamazepine Toxicity". Ann Emerg Med. 25(5): 631- 635 .

Ayoğlu FN, Ayoğlu H, Kaptan YM et al., (2009): “A Retrospective Analysis of Cases with Acute Poisoning in Zonguldak, Turkey". Türk Anest Der Dergisi. 37(4):240-248.

Baldasseroni S, Urso R, Orso F et al., (2011): Relation between serum sodium levels and prognosis in outpatients with chronic heart failure: neutral effect of treatment with beta-blockers and angiotensin-converting enzyme inhibitors: data from the Italian Network on Congestive Heart Failure (IN-CHF database). J Cardiovasc Med (Hagerstown). Oct; 12(10):723-31.

Bassioni MF, Abdel Rassoul MI, Abdel Magid LA et al., (1997): "Clinical and laboratory study of acute digitalis toxicity". M. SC Thesis at Faculty of Medicine, Alexandria University.

Bauman JL, Didomenico RJ and Galanter WL (2006): Mechanisms, manifestations, and management of digoxin toxicity in the modern era.Am $\mathrm{J}$ Cardiovasc Drug. 6(2):77-86.

Benner JP, Borloza MP, Adams M et al., (2007): "Impact of the 12-lead electrocardiogram on ED evaluation and management" Am J Emerg Med. 25: 942-948.

Buckley NA and Sanders P (2000): "Cardiovascular Adverse Effects of Antipsychotic Drugs". Drug Safety 23(3): 215- 228.

Ciszowski K and Sein Anand J (2011): "Electrocardiographic abnormalities in acute olanzapine poisonings". Przegl Lek. 68(8):422-5. Abstract.

Clancy C (2006): "Electrocardiographic Principles" In: Goldfrank's Toxicologic Emergencies 8th ed. Hoffman R.S., Nelson L.S., Howland M.A, Lewin N.A., Flomenbaum N.E. and Goldfrank L.R. (eds). The McGraw-Hill: New York. P: 51.

Delk C, Holstege CP and Brady WJ (2007): "Electrocardiographic abnormalities associated with poisoning". Am J Emerg Med. 25: 672-687.

Doyon S (2006): “Anticonvulsants" In: Goldfrank's Toxicologic Emergencies. 8th ed. Hoffman RS, Nelson LS, Howland MA, Lewin NA, Flomenbaum NE and Goldfrank LR (eds). The McGraw-Hill: New York. P: 735.
Ede M, Ye J, Gregorash L et al., (1997): Beyond Hyperkalemia: $\beta$-Blocker-Induced Cardiac Arrest for Normothermic Cardiac Operations. The Annals of Thoracic Surgery. 63(3): 721727.

George BK, Pavlos K, George T et al., (2004): "Review of clinical and toxicological features of acute pesticide poisonings in Crete (Greece) during the period 1991-2001". Med Sci Monit. 10(11): 622-7.

Goldberger AL (2006): Clinical Electrocardiography: A Simplified Approach. 7th ed. Mosby Elsevier incorporation: St Louis, Baltimore, Boston, London, New York, Oxford, Philadelphia, Sydney, Toronto, Tokyo. P: 759.

Gülğolu C and Kara IH (2005): “Acute poisoning cases admitted to a university hospital emergency department in Diyarbakir, Turkey". Hum Exp Toxicol; 24: 49- 54.

Hack JB and Lewin NA (2006): "Cardioactive steroids". In: Goldfrank's Toxicologic Emergencies 8th ed. Hoffman RS, Nelson LS, Howland MA, Lewin NA, Flomenbaum NE and Goldfrank LR (Eds). The McGraw-Hill, New York, Pp. 974- 975.

Hoffman RJ (2006): "Methylxanthines and Selective ß2-Adrenergic Agonists". In: Goldfrank's Toxicologic Emergencies 8th ed. Hoffman RS, Nelson LS, Howland MA, Lewin NA, Flomenbaum NE and Goldfrank LR (Eds). The McGraw-Hill, New York, P: 990.

Irwin RS and Rippe's JM (2006): "General considerations in the evaluation and treatment of poisoning". In: Intensive Care Medicine. 6th ed. Lippincott Williams and Wilkins Company: Philadelphia, pp. 17-35.

Jaiprakash H, Sarala N, Venkatarathnamma PN et al., (2011): "Analysis of different types of poisoning in a tertiary care hospital in rural south India". Food Chem Toxicol. 49: 248250 .

Karki P, Ansari JA, Bhandary S et al., (2004): "Cardiac and electrocardiographical manifestations of acute organophosphate poisoning". Singapore Med J. 45(8): 385- 389.

Kris LL, Movig, Hubert GM et al., (2002): Association between antidepressant drug use and hyponatraemia: a case-control study. Br J Clin Pharmacol. 53(4): 363-369.

Krysiak R and Okopie B (2007): Carbamazepineinduced hyponatremia. Pol Arch Med Wewn. 117(4):73-5.

Lai MW, Klein-Schwartz W, Rodgers GC et al., (2006): "2005 Annual Report of the American Association of Poison Control Centers; national poisoning and exposure database". Clin Toxicol (Phila). 44: 803-932.

Lheureux PE and Hantson P (2009): Carnitine in the treatment of valproic acid-induced toxicity. Clin Toxicol (Phila). 47:101-11. 
Liebelt EL, Ulrich A, Francis PD et al., (1997): "Serial electrocardiogram changes in acute tricyclic antidepressant overdoses". Critical Care Medicine. 25(10): 1721- 1726.

Lin CC, Yang CC, Phua DH et al., (2010): “An Outbreak of Foxglove Leaf Poisoning”. J Chin Med Assoc. 73(2): 97- 100.

Love JN, Enlow B, Howell JM et al., (2002): "Electrocardiographic Changes Associated with $\beta$ - Blocker Toxicity”. Ann Emerg Med. 40(6): 603-610.

Ludomirsky A, Klein H, Sarelli P et al., (1982): “Q-T prolongation and polymorphous (torsade de pointes) ventricular arrhythmias associated with organophsphorus insecticide poisoning". Am J Cardiol. 49: 1654- 8.

Madhusoodanan S, Bogunovic OJ, Moise D et al., (2002): Hyponatraemia associated with psychotropic medications: a review of the literature and spontaneous reports. Adverse Drug React Toxicol Rev. 21 (1-2): 17-29.

Mannesse CK, Puijenbroek V, Eugène P et al., (2010): Hyponatraemia as an Adverse Drug Reaction of Antipsychotic Drugs: A Case-Control Study in VigiBase.Drug Safety. 33 (7): 569578.

Marahatta SB, Singh J, Shrestha R et al., (2009): "Poisoning cases attending emergency department in Dhulikhel Hospital- Kathmandu University Teaching Hospital". KUMJ. 7(26):152- 6 .

Marar IE and Amico JA (1998): Vasopressin, oxytocin, corticotrophin-releasing factor, and sodium responses during fluoxetine administration in the rat. Endocrine. 8:13-18.

Marklund N, Enblad P and Ronne-Engström E (2007): Neurointensive care management of raised intracranial pressure caused by severe valproic acid intoxication. Neurocrit Care. 7(2):160-4.

McCaig LF and Nawar EN (2006): National Hospital Ambulatory Medical Care Survey: 2004 emergency department summary. Advance data from vital and health statistics; no 372. Hyattsville, MD: National Center for Health Statistics.

McPherson ML, Prince SR, Atamer ER et al., (1986): Theophylline-induced hypercalcemia.Ann Intern Med. 105(1):52-4.

Meulendijks D, Cyndie K, Paul AF et al., (2010): Antipsychotic-Induced Hyponatraemia: A Systematic Review of the Published Evidence. Drug Safety. 33(2): 101-114.

Pereira S, Guimarães S and Marques A (2008): Antidepressant-inducedHyponatremia. A case report in a late onset mood disorder patient. European Psychiatry. Vol. 23(2), April, S205S206.

Phillips S, Brent J, Kulig K et al., (1997): "Fluoxetine versus tricyclic antidepressants: a prospective multicenter study of antidepressants drug overdoses”. J Emerg Med. 15(4): 439- 445.
Richardson WH, Betten DP, Williams SR et al., (2007): "Nitroprusside, ACE inhibitors, and other cardiovascular agents". In: Haddad and Winchester's Clinical Management of Poisoning and Drug Overdose 4th ed. Shannon MW, Borron SW, and Burns MJ, (eds). Saunders, Elsevier. pp: 985- 996.

Rivera JA and Rivera M (1990): Organophosphate poisoning. Bol Asoc Med P R; Sep; 82(9):419-22.

Sawalha AF, Sweileh WM, Tufaha MT et al., (2010): "Analysis of the Pattern of Acute Poisoning in Patients Admitted to a Governmental Hospital in Palestine". Basic Clin Pharmacol Toxicol. 107: 914- 918.

Shannon M (1993): "Predictors of Major Toxicity after Theophyiline Overdose". Ann Intern Med; 119: 1161-1167.

Siegler EL, Tamres D, Berlin JA et al., (1995): Risk factors for the development of hyponatremia in pscychiatric patients. Arch Intern Med.155:953-957.

Singh B and Unnikrishnan B (2006): "A profile of acute poisoning at Mangalore (South India)". J Clin Forensic Med. (13): 112- 116.

Sonnenblick M, Friedlander Y, and Rosin AJ (1993): Diuretic-induced severe hyponatremia. Review and analysis of 129 reported patients. Chest. 103:601-603.

Thacker D and Sharma J (2007): Digoxin toxicity. Clin Pediatr (Phila) ; Apr ; 46(3):276-9.

Thomas A and Verbalis JG (1995): Hyponatremia and the syndrome of inappropriate antidiuretic hormone secretion associated with drug therapy in psychiatric patients. CNS Drugs. 4 (5): 357-69.

Vucicevic Z, Degoricija V, Alfirevic Z et al., (2007): Fatal hyponatremia and other metabolic disturbances associated with psychotropic drug polypharmacy. Int J Clin Pharmacol Ther. 45 (5): 289-93.

Wagner GS (2008): "Basic Concepts". In: Marriott's Practical Electrocardiography, 11th ed. Wagner G.S. (Editor). Lippincott Williams \& Wilkins: New York. P: 2

Watson WA, Litovitz TL, Klein-Schwartz W et al., (2004): "2003 Annual Report of the American Association of Poison Control Centers; Toxic Exposure Surveillance System". Am J Emerg Med. 22:335- 404.

Wells K, Williamson M, Holstege CP et al., (2008): "The association of cardiovascular toxins and electrocardiographic abnormality in poisoned patients". Am J Emerge Med. 26(8): 957- 959.

Yurumez Y, Yavuz Y, Saglam H, Durukan P et al., (2009): "Electrocardiographic findings of acute organophosphate poisoning”. J Emerg Med. 36(1): 39- 42. 
الملخص العربي

دراسة تغيرات رسم القلب الكهربائي المصاجبة لحالات التسمم الحادة بمركز علاج التسمم

منى محمد حشمت وعائشة إبراهيم مقلد 1 و رغدة غنيمي الثيخّ2 إيناس إبراهيم المداح' و أميرة وهدان أمين 1

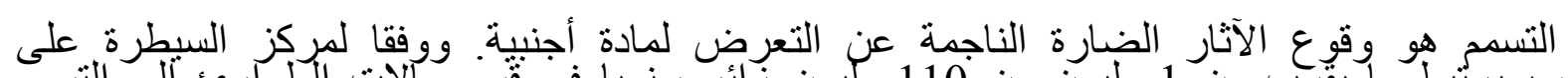

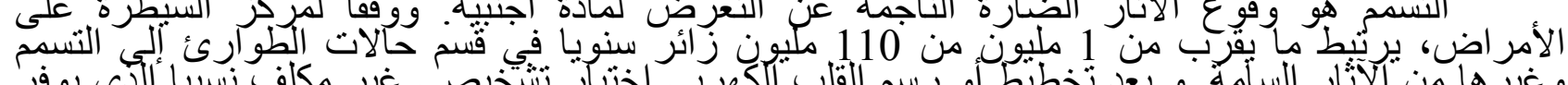

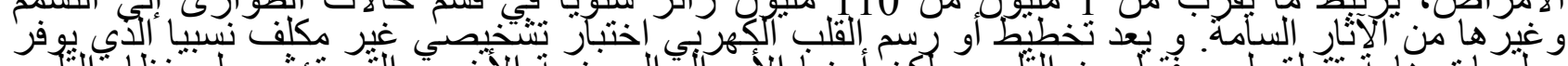

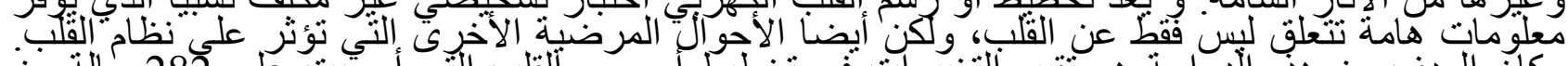

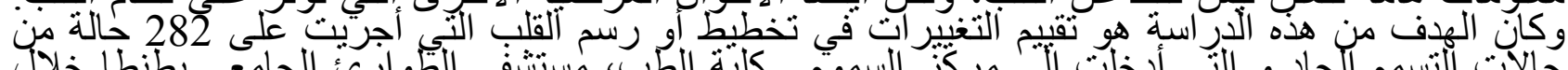

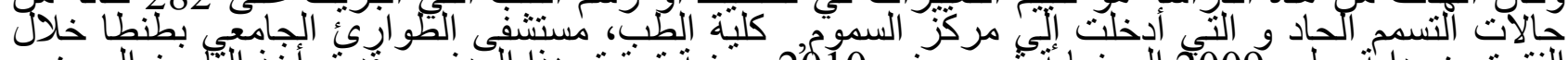

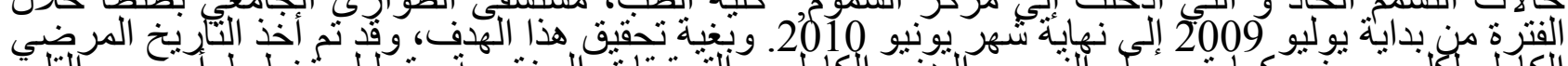

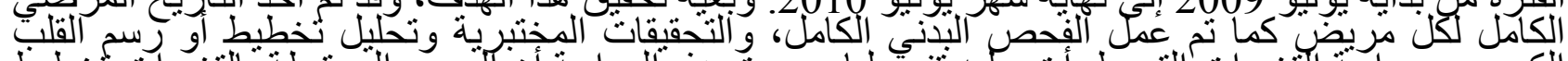

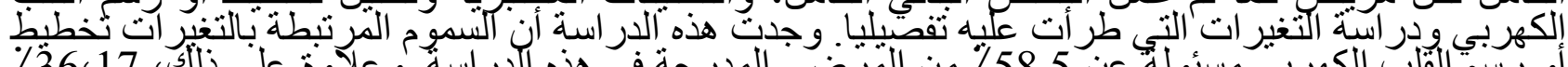

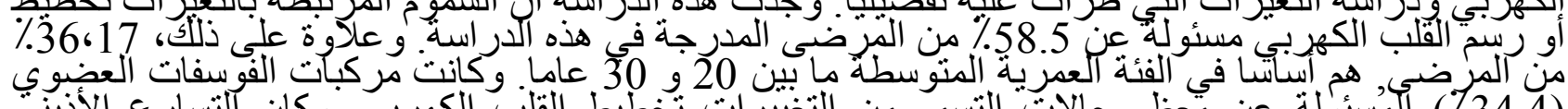

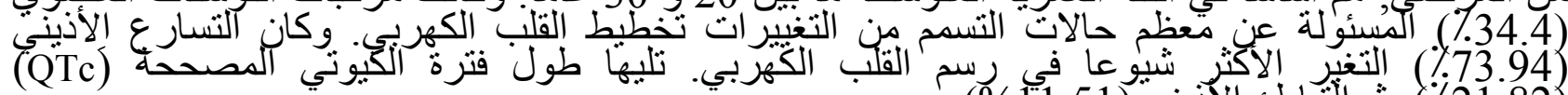
(\%)

1' قسم الطب الشرعي و السموم الإكلينيكية كلية الطب جامعة طنطا

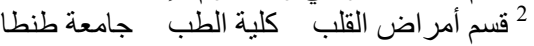

